\title{
Huitzilopochtli-Vitzeputze: cómo se convirtió el dios guerrero mexica en una imagen diabólica en el uso del idioma alemán*
}

\author{
Ursula THIEMER-SACHSE \\ Freie Universität Berlin
}

Hoy más que nunca el recuerdo del quinto centenario de la Conquista y explotación de los indígenas del continente americano nos motiva a tratar la influencia recíproca entre el viejo y el nuevo mundos. El descubrimiento de lo nuevo y la apertura de nuevas fuentes de recursos estuvieron acompañados por una brutalidad desmedida en contra de la población autóctona. Los conquistadores se apropiaron de las riquezas del mundo al otro lado del océano atlántico, y los indigenas que las habían creado, junto con el ambiente en que se encontraban, fueron sometidos por los invasores. La gente fue esclavizada o forzada al trabajo mediante medios de explotación inhumanos. Las culturas nativas sufrieron un choque brutal y, por lo general, fueron destruidas o deformadas en la medida que dificultaban el sometimiento a los representantes del poder colonial.

Esto no excluyó que junto con la apropiación de muchos tesoros, como joyas de oro y piedras preciosas, llegaran a Europa, en gran escala, expresiones culturales totalmente diferentes cuyo origen no fue considerado como amerindio. Se puede nombrar una serie considerable de plantas cultivadas por los indígenas americanos que cambiaron la manera de vivir y las costumbres de los habitantes del viejo continente, entre ellas la papa, el maiz, el jitomate, el chile, el tabaco, el girasol y el índigo.

Además de la explotación y la violencia se ejerció una enorme influencia espiritual en los indígenas, especialmente mediante las actividades de los misioneros. La introducción del catolicismo implicó el atropello de diversos conceptos culturales. La comprensión de la visión del mundo de los otros - conquistadores y conquistados - fue muy reducida por ambas partes. De ello resultó una interpretación muy distinta de su manera original de pensar.

Testimonio elocuente de ello es el proceso de conciliación de las creencias religiosas. Se puede registrar una mezcla de visiones e ideas de origen diverso no solamente entre los indígenas sino también entre la población mestiza en

* Versión en espańol revisada por Israel Rubén Garciadiego Ramos. 
proceso de formación. El pensamiento amerindio también influyó indirectamente en la visión del mundo de los europeos, la cual se transformó en el tiempo de los grandes descubrimientos. Esto se refleja, entre otras cosas, en varias denominaciones y conceptos amerindios que fueron utilizados más frecuentemente que los relatos mismos de la Conquista española difundidos en Europa. Un ejemplo muy interesante, en este sentido, lo representa el caso del nombre del dios principal mexica: Huitzilopochtli.

En el proceso de la Conquista de México, durante 1519 a 1521, los conquistadores españoles se vieron confrontados con culturas de sociedades muy desarrolladas, de carácter totalmente diferente en comparación con las que habían encontrado entre los indígenas de las Antillas, un cuarto de siglo antes. Provocaron batallas sangrientas en las cuales vencieron a los ejércitos de los indigenas mexicanos, especialmente a los de los pueblos nahua-hablantes del México central, y los subyugaron.

Los guerreros indígenas, bien armados en comparación con los de otros paises del continente, resistieron en lucha desesperada los intentos de los españoles de oprimirlos; sin embargo, no pudieron ser los vencedores. No obstante, tuvieron éxitos temporales que combinaron con ceremonias que deberían garantizarles fortuna en la guerra. En ese sentido, los indígenas trataron a los prisioneros de guerra españoles siguiendo sus costumbres. Los españoles cautivos durante las batallas desempañaron un papel importante para los mexicas. Por eso fueron sacrificados a los dioses. En las luchas por la conquista definitiva de la capital mexica, la magnífica ciudad insular de México-Tenochtitlan, los conquistadores fueron testigos a distancia de tales ceremonias, en las que algunos de sus combatientes dejaron la vida sobre la piedra de los sacrificios. ${ }^{1}$

Los fanáticos religiosos entre los conquistadores y misioneros españoles interpretaron como fantasmagorias del diablo el sacrificio humano, así como muchas de las otras ceremonias que practicaban los indígenas.

El hecho de que el sacrificio los empezara a afectar directamente, después de la muerte de algunos de sus compañeros de armas, reforzó la imaginación del papel de diablo que habian otorgado sobre todo al dios principal de los mexicas, al dios guerrero Huitzilopochtli, que había tenido su origen en el héroe tribal.

Los indígenas de México sacrificaban a hombres en honor de la mayoría de los dioses de su panteón. Tales sacrificados fueron considerados como encar-

I Véase Bernal DiAz DEL CAstillo, Wahrhaftige Geschichte der Entdeckung und Eroberung von Mexiko. Fráncfort del Main, 1982, p. 412; Alejandro de HUMBOLDT, Vues des cordillères, et monuments des peuples indigènes de l'Amérique. París, 1810, p. $95.2 \mathrm{tt}$. 
naciones de los dioses, y simbolizaban el rejuvenecimiento y robustecimiento del respectivo numen. Sin embargo, para los conquistadores españoles, los cronistas y todos los que relataron y escribieron acerca del modo de vivir y de la cultura de los antiguos mexicanos, el dios Huitzilopochtli se transformó en el prototipo de la violencia terrible que solicitaba víctimas humanas y que como contraparte del dios cristiano había engañado a los pueblos.

Finalmente, esta caracterización diabólica del dios guerrero mexica provocó que utilizaran su nombre aisladamente de los contextos sociales para denominar lo inexplicablemente cruel.

Este nombre, "Huitzilopochtli", se convirtió en el diablo en persona que pierde a los hombres, solamente por el papel especial del numen dentro del panteón mexica, ignorando la semántica de los componentes del nombre indígena: colibri (huitzilin) del lado izquierdo (opochtli), es decir, del sur.

Para los indigenas, el diablo, como la personificación de lo malo, era algo nuevo. Modificado por los misioneros cristianos, el dios perdió su carácter ambivalente. Los monjes también vieron en Huitzilopochtli solamente al diablo en persona. Como tal, esta figura entró en el concepto de los europeos.

Su nombre, ya estropeado, fue degradado y se convirtió en un "coco" para los niños, mientras que la idea de que Huitzilopochtli era el diablo en persona perdia color o iba desapareciendo totalmente. Con lo descrito en las líneas que preceden se puede observar el cambio de significado, así como la transformación del contenido y la forma de designación del dios guerrero mexica.

Observemos unos ejemplos interesantes de la transformación mencionada:

En la pieza para títeres de los años 1881 y 1882 Doctor Fausto (denominada Schwiegerlingsches Puppenspiel por su autor), Vitzliputzli pertenece a las furias. Mediante un libro de magia negra, el doctor Fausto conjura a los fantasmas. Entre ellos aparece uno de los espíritus y, al preguntársele por su nombre, declara: "Vitzliputzli, der Niedliche" ("Soy Vitzliputzli, el gracioso"). Con base en esto se desarrolla el diálogo siguiente: Fausto: "Nun, das letztere könnte allenfalls wegbleiben, denn etwas niedlicheres habe ich noch nie gesehen" ("Pues bien, lo último, de todos modos, se podría dejar aparte, pues algo más gracioso no he visto nunca"). Vitzliputzli: "Du irrst, Faust, alle Höllenschönheiten sind auf mich versessen" ("Te equivocas, Fausto, todas las bellezas del infierno están locas por mí"). A este combate de ironia sigue la confirmación de Fausto que declara que no puede aceptar a Vitzliputzli como sirviente, pues el último ha explicado: "Ich bin so geschwind wie die Schnecke am Zaun" ("Soy tan rápido como el caracol en el seto"). ${ }^{2}$

2 A. BIElschowsKY, Das Schwiegerlingsche Puppenspiel vom Doktor Faust. Separatum in der Berliner Stadtbibliothek, 1881-1882 (?), p. 16. 
En esta pieza de títeres, al antiguo dios principal mexica ha sido convertido en algo estrafalario, pues en este episodio también se le han asignado habilidades especiales, incluso cuando se ha aludido a su aparición desagradable.

Las piezas de títeres o de guiñol que nos interesan en relación con la apariencia de Vitzliputzli se pueden encontrar en el siglo XIX en muchas regiones de las zonas germanohablantes. En una de esas interpretaciones se ha podido constatar que desde comienzos del siglo pasado, entre los fantasmas o espíritus que el doctor Fausto cita, aparece Vitzliputzli como uno de los diablos, denominado de 'diferentes maneras, por ejemplo: Vizlibuzli, Virzlipurzli, Fitzliputzli. En una de las variantes que se presentaron al público en la ciudad de Leipzig, Vitzliputzli aparece junto a otro espíritu que se llama "Mexiko". La cualidad deseada siempre es la rapidez del espiritu sirviente, la cual es comparada con la rapidez de un caracol, de una flecha, de un pájaro, de una bala de fusil, así como de un barco en el mar. ${ }^{3}$ El doctor Fausto se declara descontento con el esfuerzo ofrecido en su apoyo y lo ahuyenta al infierno. ${ }^{4}$ Es importante hacer notar que en la variante de Leipzig se hace una mención de México, aunque aparentemente sin vínculo alguno entre ambos espíritus. ${ }^{5}$

Se puede comprender la importancia de esta figura en las piezas de títeres, observando que en los diccionarios se encuentra la palabra "Vitzliputzli", explicada como sigue: "Teufelsgestalt im Puppenspiel; entstellt aus aztekisch Huitzilopochtli oder Uitzilopochtli" (Figura del diablo en el teatro de títeres; alterado del náhuatl Huitzilopochtli o Uitzilopochtli). ${ }^{6}$ Por eso es aún más comprensible que Johann Wolfgang von Goethe no haga aparecer a la figura del Vitzeputze en ninguna parte de su Fausto. Las fuentes en las cuales se inspiró aparentemente no lo estimularon en ese sentido; no se encuentra ninguna huella ni en los fragmentos ni en el "Urfaust" (Fausto original). Sin embargo, es esencial lo que Goethe expresa, en 1829 , en una carta a su amigo Karl Friedrich Zelter acerca de la fábula y el nombre del diablo.

Explica que no sabe contestar la pregunta respecto del origen del nombre de Mephistopheles (Mefistófeles). Piensa que la leyenda del doctor Fausto tuvo su origen en el siglo XVI y se desarrolló durante el siglo XVII. Lo esencial era que los conjuradores protestantes no tenían que temer directamente a la excomunión eclesiástica. ${ }^{7}$

${ }^{3}$ Ibid., pp. $35,45-47$.

${ }^{4}$ Ibid., p. 29.

${ }^{5}$ Before Cortés. Sculpture of Middle America. A centennial exhibition at the Metropolitan Museum of Art. Nueva York, 1970. (Nr.305)

'Meyer's Neues Lexikon, t. 14. Leipzig, 1976.

7 Johann Wolfgang vON GOETHE, Faust. Leipzig, Gesamtausgabe, 1958, pp. 600601. 
El espíritu fáustico del renacimiento, que lucha contra el transcurso del tiempo con sus conceptos del ser humano y del mundo, se podría conciliar verdaderamente con otra visión de Huitzilopochtli, el dios guerrero mexica. En este punto es importante destacar que se podía mezclar el término del "butz", como se explica en el diccionario alemán de los hermanos Jacobo y Guillermo Grimm: "Popanz" ("espantajo"), "Vogelscheuche" ("diablo disfrazado, enmascarado"). Allí también se habla de "butzen gehen oder laufen zur fastnachtszeit" ("andar o correr como espantajo en el tiempo de cuaresma").

Como los hermanos Grimm pudieron constatar, esa palabra "butz, putz" estaba estrechamente relacionada con el verbo "putzen" ("ataviarse, vestirse, componerse, disfrazarse"). En este contexto subrayaron que faltaba el respectivo verbo en el alemán medieval (Alt- und Mittelhochdeutsch: alto alemán antiguo y alto alemán medio), pero que la utilización del sustantivo "butze" en el alto alemán medio para "larva, diabolus" ("la larva, el diablo") garantizaba el uso de un verbo correspondiente.

"Butz" estaba relacionado con "butzemann" (hombre butz), ${ }^{8}$ demostrado muy tempranamente por la observación de Martín Lutero dentro de sus famosos discursos de mesa: "das rechte recht ist zum schemen und putzemann worden" ("el derecho justo / o verdadero derecho / se ha convertido en un fantasma y un 'putzemann" ").

De la misma manera se puede interpretar al "butzemann" que baila alrededor de la casa, como el legado a la posteridad por la colección de poemas y cantos populares del libro Des Knaben Wunderhorn (El clarín milagroso del muchacho), escrito durante el siglo XIX. ${ }^{10}$ En el mencionado diccionario alemán también se resalta que tener un "butzen im leib" ("'butz' en el cuerpo") era comprendido como un mal escondido, y que el "butzelmann" o "butzenmann" además podía tener el sentido de "pene"."

En los diccionarios del folclor alemán también se encuentran interpretaciones semejantes que establecen, sobre todo, las relaciones de ese término con la pequeñez del ser, su apariencia como duendecillo, como espantajo especial para niños. ${ }^{12}$ En el diccionario de los hermanos Grimm se considera Vizlipuzli,

'Jakob y Wilhelm GrImM, Deutsches Wörterbuch, t. II. Leipzig, 1860, tomo II, pp. 589,592 y 594.

${ }^{9}$ Ibid., p. 595.

${ }^{10}$ Kinderreime y Kinderlieder aus, Des Knaben Wunderhorn. Berlín, 1980, p. 52.

11 J. y W. GRIMM, op. cit., pp. 590-591.

${ }^{12}$ Véase Handwörterbuch des deutschen Aberglaubens, E. HOFFMANN-KRAYER y H. BÄCHTOLD-STÄUBLI, eds. Berlín, Leipzig, 1927; 1935-1936, t. I: Butz, Butze(n)mann, Butte, Bd. III: Puppe.-Trübners Deutsches Wörterbuch. Berlín, 1939: Butze.-Heinz 
nombre deformado del dios mexicano utilizado para el diablo, como denominación para el ser antes mencionado ("entstellter mexikanischer Gottname, für Teufel"). ${ }^{13}$

Pero sabemos poco de cuándo y cómo esta denominación encontró aceptación como término especial dentro del uso general del idioma alemán. A mediados del siglo XVIII, sea como fuere, se habló extensamente de "Vitzilopuchtli, Vitzliputzli, Vizlipuzli" como el "dios malo" ("bösen Gott") de México. Se puede encontrar una explicación en el voluminoso Gran diccionario universal de todas las ciencias y artes, que se orienta con la descripción publicada por Olfert Dapper y donde entran, además, detalles de la leyenda de peregrinación de los mexicas, la cual se considera como una leyenda ordenada por ese ídolo ("abgott") o diablo ("teufel"). ${ }^{14}$

Todavía a fines del siglo XIX las imágenes de la fisonomía de este dios mexica eran en gran parte grabados, los cuales se basaban en los dibujos publicados en los compendios de las primeras etapas de la época moderna. La siguiente información, dada en un diccionario de conversación de 1897 , lo demuestra: "Vitzliputzli (Huitzilopochtli), der mit Menschenopfern verehrte Kriegsgott der alten Mexikaner (Azteken), den man in Kolossalgestalt, mit Goldmaske u. den Leib mit goldener Schlange umwunden, darstellte" ("V., dios guerrero de los antiguos mexicanos [aztecas] venerado mediante sacrificios humanos, a quien representaban en una imagen colosal con una máscara de oro y un cuerpo envuelto por una víbora dorada"). ${ }^{15}$

También se conoce un naipe de tarot del primer cuarto del siglo XIX, que presenta una figura del dios enfrente de una pirámide egipcia acompañada por el texto "Vitziliputzli". ${ }^{16}$

No se deben pasar por alto las relaciones entre el uso de este nombre y su simbolismo dentro del conjunto de relatos sobre la Conquista de México y sus

Küpper: Wörterbuch der deutschen Umgangssprache. Hamburgo, 1966, tomo IV: Berufsschelten und Verwandtes: Butz, Butzemann.-Wossidio-Teuchert: Mecklenburgisches Wörterbuch. Berlin/Neumünster, 1957, t. 2: butz, Butz, Butzebaba, butzen, Butzer, butzig, Butzkopp.-Johann Carl Dăhnert: Platt-Deutsches Wörter-Buch nach der alten und neuen Pommerschen und Rügischen Mundart. Stralsund, 1781 (1822): Butz, Butzen.

13 J. y W. GRIMM, op. cit., t. XII, pp. 386-387.

14 Véase Großes Universal-Lexikon Aller Wissenschaften und Künste, welche bishero durch menschlichen Verstand und Witz erfunden wurden, t. III. Leipzig y Halle, 1746, p. 402.

${ }^{15}$ Meyers Konversations-Lexikon, t. XVII. Leipzig-Viena, 1897.

${ }^{16}$ Detlef Hoffmann, Don Quijote Pelikan Vitzliputzli. Tarocke mit französischen Farben. Bielefeld, 1968, pp. 26-29. (Deutsches Spielkarten Museum in Bielefeld e.V.) 
representaciones gráficas. Aparentemente, el grabado en cobre denominado "Vitzliputzli idolum Mexicanorum", publicado en la obra de Arnoldo Montanus, jugó un papel decisivo en favor de eso; primeramente fue publicado en 1671 en Amsterdam, en idioma holandés, y traducido al alemán por Olfert Dapper en 1763 , se publicó dentro de un voluminoso libro titulado Die unbekannte Neue Welt oder Beschreibung des Weltteils Amerika (El nuevo mundo desconocido o descripción del continente América). ${ }^{17}$ Sin embargo, el dios ya se encontraba dibujado de la misma manera en la obra de Teodoro de Bry, la cual se titula Zwölfter Theil der Newen Welt (Duodécima parte del Nuevo Mundo), publicada en 1623, que es una descripción basada en las obras de los cronistas españoles Antonio de Herrera y Tordesillas y José Acosta. En la obra de Bry, el dios aparece como monstruo antropozoomorfo "Hoitzili pochtli summus Mexicanorum Deus". ${ }^{18}$

Al parecer, estos grabados en cobre se difundieron ampliamente y los textos acompañantes se hicieron populares, pues como relatos históricos atrajeron la atención hacia un mundo extraño y exótico, representándolo por primera vez para el público alemán. Ésas parecen ser las fuentes primordiales para la difusión del término "Vitzeputze" como diabólico.

Además, se puede constatar que la imaginación general acerca de los misteriosos cultos entre los pueblos indígenas era una parodia de las ceremonias cristianas y los interpretaban como provocaciones del diablo comparándolos con acciones de simios reflejadas en las actividades humanas, esto implicaba la combinación de diferentes símbolos. Llamaban "Fitzliputzli" a una pequeña figura de metal que representaba a un mono, fabricada por artesanos mexicanos a principios de la época colonial, cuya apariencia recuerda tradiciones indígenas precortesianas. Su reproducción gráfica más temprana pertenece al siglo XVII. ${ }^{19}$ En el México antiguo, el mono representa la deificación de la alegría de la vida, del gusto y de los bailes, y fue equiparado asi con el dios guerrero.

Tal visión mística de Vitzliputzli como figura simbólica de la antigua vida mexicana se encuentra también, aunque artísticamente distanciada, en una de las escenografias que proyectó el pintor y escultor alemán Karl Friedrich Schinkel para la representación de la opera Fernand Cortez oder: die Erobe-

17 Dapper, “Die unbekannte Neue Welt”, cuadro 248.

${ }^{18} \mathrm{De}$ Bry, Amerika oder die Neue Welt, pp. 2 y 129; en la edición moderna: Leipzig, Weimar, segunda parte; la figura 22 está en la p. 17, así como el cuadro 56. Este dibujo aparentemente era el modelo para el naipe de tarot mencionado arriba.

${ }^{19}$ Véanse Before Cortés...; Johann Georg KeYBLER, Fortsetzung neuester Reisen durch Teutschland. Bohmen, Ungarn, Hannover, 1747, p. 1192. 
rung Mexiko's (Hernán Cortés o la Conquista de México). ${ }^{20}$ Esta ópera de Gaspare Spontini tuvo un significado especial para la Prusia de después de las guerras de liberación de la ocupación napoleónica. Schinkel no se basó en ilustraciones con una reflexión científica y fiel a los hechos como la famosa obra de Alexander von Humboldt Vues pittoresques des cordillères (Vistas pintorescas de las cordilleras). ${ }^{21}$

Vitzliputzli había hecho su entrada en la literatura barroca, y como configuración del diablo perteneció a los mitos más notables acerca del Nuevo Mundo. 22

Heinrich Heine trató el asunto de una nueva manera, se dice que criticó su época de manera frívola con la retrospectiva de acontecimientos bastante ajenos como la Conquista de México. ${ }^{23}$ En 1851 publico "Vitzliputzli" como el último poema de su libro Romancero, y con ello posibilitó una visión crítica de la historia de los acontecimientos y conceptos, dando, a su vez, el ímpetu para un tratamiento posterior de la materia. Heine demostró qué influencia puede ejercer una interpretación tendenciosa de la historia en la enseñanza y en la educación - sobre todo en la popular-declarando:

Nur ein Räuberhauptmann war er, Der ins Buch des Ruhms einschrieb Mit der eignen frechen Faust, Seinen frechen Namen: Cortez. Unter des Kolumbus Namen Schrieb er ihn, ja dicht darunter, Und der Schulbub' auf der Schulbank lernt auswendig beide Namen [...]

Heldenschicksals letzte Tücke Unser Name wird verkoppelt Mit dem Namen eines Schächers In der Menschen Angedenken. ${ }^{24}$

${ }^{20}$ Ulf BanKmanN, "Der Haupttempel von Mexiko-Tenochtitlan im Buhnenbild Karl Friedrich Schinkels", en Mexicon, núm. 4. Berlín (1982) 3, pp. 38-42.

${ }^{21}$ Véase Alexander von HUMBOLDT, Vues des cordillères.

${ }^{22}$ Friedrich W. SIXEL, "Christoph Kolumbus war kein Freund von mir", en Mythen der Neuen Welt. Zur Entdeckungsgeschichte Lateinamerikas, hrsg. von Karl-Heinz Kohl. Berlin, 1982, pp. 225-226; figura 216.

${ }^{23}$ Heinrich Heine's Sämtliche Werke. Neue Ausgabe in 12 Bänden. Hamburgo, 1887, t. II: Romancero-letze Gedichte, pp. 48 y ss.; véase Gordon BROTHERSTON, "Huitzilopochtli and what was made of him", en Mesoamerican Archaeology, ed. de N. HAMMOND. Duckworth, 1974, p. 163.

${ }^{24}$ Heinrich Heine's Samtliche Werke..., pp. 48-49. 
(Solamente era un capitán de bandoleros

que inscribió en el libro de la gloria

con el propio puño atrevido

su nombre petulante: Cortés.

Bajo el nombre de Colón

Lo escribió, sí, justo debajo,

y el alumno en su banco de escuela

aprende de memoria ambos nombres -

[...]

Última perfidia de la aventura del héroe:

Nuestro nombre es enganchado

al nombre de un mal ladrón

en la memoria de los hombres.)

Heine definió el viaje de Cristóbal Colón al occidente como un esfuerzo heróico, una ampliación del mundo que la humanidad, cansada de Europa, le agradeció; después se dedicó a los acontecimientos de la Conquista, tema que trató aparte. También realizó una evaluación determinada por una visión discrepante del mundo indígena centromexicano en tiempos de la Conquista. Lleno de ironía, no le hizo justicia al último tlatoani mexica: Moctezuma, quien no adivinó las intenciones de Cortés. Sin embargo, con base en las ideas generales contemporáneas, no pudo procurarse una visión sin prejuicios de las creencias mexicas y de su manifestación en las ceremonias y las representaciones de sus dioses.

Heine declara:

Dieser unzivilisierte

Abergläubisch blinde Heide

Glaubte noch an Treu' und Ehre

Und an Heiligkeit des Gastrechts.

(Este pagano salvaje

supersticiosamente ciego

todavía creía en la lealtad y el pundonor

y en lo sagrado de la hospitalidad.)

E irónicamente agrega:

Wie das Festspiel war betitelt, weiB ich nicht. Es hieB vielleicht:

"Span'sche Treue!" doch der Autor

Nannt sich Don Fernando Cortez. ${ }^{25}$

${ }^{2 s}$ Ibid., p. 50. 
(Cómo se tituló la comedia, no lo sé. Tal vez se llamaba "lealtad española", pero el autor se llamó don Fernando Cortés.)

No queda claro qué relatos historiográficos sirvieron de base a Heine en su descripción de los acontecimientos de la noche llamada por los españoles "triste", es decir, su derrota en México-Tenochtitlan que fue reconquistada por los guerreros mexicas en la noche del 30 de junio de 1520. Sin embargo, se puede constatar que Heine se distancia claramente del comportamiento de los conquistadores españoles y reacciona con declaraciones severas en contra de una glorificación de sus crimenes, por ejemplo:

Viele Spanier waren gleichfalls

Schwer bepackt mit jenem Golde,

Das sie jüngst erpresst, erbeutet

Ach, die gelbe Sündenlast

Lăhmte, hemmte sie im Kampfe,

Und das teuflische Metall

Ward nicht bloß der armen Seele,

Sondern auch dem Leib verderblich. ${ }^{26}$

(Muchos de los españoles iban cargados

con el peso de oro

que ellos habían arrebatado y robado

al enemigo antes

¡ay! la carga amarilla del pecado

los paralizó, los estorbó en la lucha,

y el metal diabólico

fue nocivo no solamente para la pobre alma

sino también para el cuerpo.)

Heine, sin embargo, solamente tuvo una visión imprecisa del dios principal mexica, de su tiempo y de sus actividades. Se basó en las descripciones ya mencionadas y lo vio reflejado, como dice, en los colosales edificios-monstruo de carácter egipcio, babilonico y asirio. ${ }^{27}$ Refiriéndose a escaleras con rampas que conducian arriba, en zigzag, hacia la plataforma, Heine sigue la descripción europea a la que le faltó una base de fuentes reales, por ejemplo, los testimonios de códices con pictografia que en su tiempo eran de fácil acceso.

26. Ibid., pp. 52 y ss.

${ }^{27}$ Ibid., p. 54. 
No era del interés de Heine reflejar fielmente los hechos en el México antiguo. Por eso sigue la descripción del dios principal mexica que, sin embargo, le parece ridícula:

Dort auf seinem Thron-Altar

Sitzt der große Vitzliputzli, Méxiko's blutrünstiger Kriegsgott, Ist ein böses Ungethüm.

Doch sein Äußres ist so putzig, So verschnörkelt und so kindisch, Dass er trotz des innern Grausens Dennoch unsre Lachlust kitzelt Und bei seinem Anblick denken Wir zu gleicher Zeit etwa An den blassen Tod von Basel Und an Brüssel's Mannken-Piss. ${ }^{28}$

\author{
(Allí en su trono-altar \\ está sentado el gran Vitzliputzli, \\ dios guerrero de México sediento de sangre, \\ es un monstruo feroz. \\ Pero su apariencia es tan graciosa, \\ tan recargada de adornos y tan pueril \\ que a pesar del espanto interior \\ nos impulsa a reir - \\ $Y$ al verlo pensamos \\ al mismo tiempo de cierta manera \\ en la pálida muerte de Basilea \\ $y$ en el hombrecillo meante en Bruselas.)
}

En este contexto, Heine habla de los sacrificios humanos que los mexicas celebraron con los prisioneros españoles. Para él lo esencial es la comparación de la comunión con lo divino, transformada totalmente en el rito cristiano de la Santa Cena. Heine ve irónicamente la forma en que los españoles se quedaron atónitos ante tal ceremonia:

Diesmal aber, bei den Wilden, War der Spaß sehr roh und ernsthaft Aufgefasst: Man speiste Fleisch, Und das Blut war Menschenblut. 
Diesmal war es gar das Vollblut Von Altchristen, das sich nie, Nie vermischt hat mit dem Blute Der Moresken und der Juden. Freu dich, Vitzliputzli, freu dich, Heute gibt es Spanierblut...29

(Esta vez, sin embargo, entre los salvajes la broma era muy cruda y considerada importante:

comieron carne, y la sangre era sangre humana.)

(Esta vez era incluso la sangre pura de cristianos renombrados la que nunca jamás se había mezclado con la sangre de los moriscos y los judios. ¡Alégrate, Vitzliputzli, alégrate! Hoy se ofrece sangre española...)

Heine da una visión de los acontecimientos caracterizada por una ironía distanciada; y no llega a dar una descripción realista cuando ilustra la relación entre la deidad indígena y su supremo sacerdote:

Süßlich grinsend, grimmig schäkernd, Spricht der Priester zu dem Gotte:

"Vitzliputzli, Putzlivitzli, Liebstes Göttchen Vitzliputzli!

Hast dich heute amüsiert, Hast gerochen Wohlgerüche!

'Heute gab es Spanierblut -...'",30

(Empalagosamente mostrando los dientes, rabiosamente chacoteando el sacerdote dice al dios: "¡Vitzliputzli, Putzlivitzli, muy querido diosito Vitzliputzli!

Hoy te has divertido, ¡has respirado perfumes!

'Hoy ha habido sangre española -...'")

${ }^{29}$ Ibid., p. 56.
${ }^{30}$ Ibid., p. 58. 
Sin embargo, reflexionando de modo poco usual, Heine logra poner las cuestiones decisivas en discusión, cuestiones que ya existían con relación a la Conquista y que eran esfuerzos para comprenderla. En ese contexto parece ser esencial que Heine ponga en duda, impasiblemente, las razones del acontecimiento histórico de la Conquista en contra de todo eurocentrismo:

Lass uns siegen, liebes Göttchen, Putzlivitzli, Vitzliputzli!

"O, verderbe unsere Feinde, Diese Fremden, die aus fernen und noch unentdeckten Ländern $\mathrm{Zu}$ uns kamen übers Weltmeer "Warum ließen sie die Heimat? Trieb sie Hunger oder Blutschuld?

[...]

"Was ist ihr Begehr? Sie stecken Unser Gold in ihre Taschen, Und sie wollen, dass wir droben Einst im Himmel glücklich werden!...

"Menschen sind sie und nicht schöner, Als wir Andre, Manche drunter Sind sie hässlich wie die Affen; Wie bei diesen, sind behaart "Die Gesichter, und es heißt, Manche trügen in den Hosen Auch verborgne Affenschwänze Wer kein Aff', braucht keine Hosen". ${ }^{31}$

(“ $\mathrm{i} H$ Háznos vencer, querido diosito Putzlivitzli, Vitzliputzli!

" $i$ Oh, destruye a nuestros enemigos! a estos forasteros que vinieron acá por el océano de paises lejanos y todavía no descubiertos "¿Porqué dejaron su patria? ¿Los movió el hambre o el homicidio? [...]

"Hombres son y no más bellos que nosotros, algunos de ellos

${ }^{31}$ Ibid., pp. 58-59. 
son feos como los monos, como ellos son peludos

"los rostros, y se dice

que algunos llevan rabos de monos

escondidos en sus pantalones -

Quien no es mono, no necesita pantalones".)

En la interpretación de Heine, la alternancia de los términos "mono-diabloVitzliputzli" es utilizada de manera muy interesante como medio estilístico para poner en duda la visión europea de los amerindios, hace uso del punto de vista indigena hacia los europeos.

Heine se expresa más claramente aún:

"Auch moralisch hässlich sind sie,

Wissen Nichts von Pietät.

Und es heißt, daß sie sogar

Ihre eignen Götter fräßen!

"O, vertilge diese ruchlos

Böse Brut, die Götterfresser -

Vitzliputzli, Putzlivitzli,

Lass uns siegen, Vitzliputzli!"32

("También son feos moralmente, no saben nada de piedad,

iy se dice que incluso

tragan a sus propios dioses!

"Oh,jextirpa a esa mala ralea

desalmada, a los comelones de dioses! -

Vitzliputzli, Putzlivitzli, ¡Háznos vencer, Vitzliputzli!”)

Aquí Heine muestra la visión del "buen salvaje" determinada por el romanticismo, desarrollada durante la Época de las Luces y legada a la posteridad, como contrapuesta a la censura del hombre europeo. Pero no está totalmente de acuerdo con una glorificación de lo exótico, sino que se apodera de la mitología, de la sabiduría de los proverbios alemanes y de las representaciones amerindias para mezclarlas y combinarlas con su opinión respecto de cómo se tiene que interpretar el proceso histórico y cómo se relacionan las antiguas profecías y la realidad experimentada y sufrida:

32 Ibid., p. 59. 
"In Erfüllung geht die böse, Uralt böse Prophezeiung "Von des Reiches Untergang Durch die furchtbar bärtgen Männer, Die auf hölzernem Gevögel Hergeflogen aus dem Osten.

"Auch ein altes Sprichwort gibt es:

Weiberwille, Gotteswille, Doppelt ist der Gotteswille, Wenn das Weib die Mutter Gottes.

"Diese ist es, die mir zürnet, Sie, die stolze Himmelsfürstin, Eine Jungfrau sonder Makel, Zauberkundig, wunderthätig. "Sie beschützt das Spaniervolk, Und wir müssen untergehen. Ich, der ärmste aller Götter, und mein armes Mexiko". ${ }^{33}$

("Se cumple la mala, la muy vieja mala profecía "de la derrota del reino por los hombres terriblemente barbudos que volaron acá del oriente sobre pájaros de madera.

"También hay un proverbio antiguo:

Voluntad de mujer-voluntad de Dios.

Doble es la voluntad de Dios si la mujer es Madre de Dios.

"Ésta es la que se enoja conmigo, ella, la princesa orgullosa del cielo, una virgen intachable, hechicera, milagrosa.

"Ella protege al pueblo español.

$Y$ nosotros tenemos que perecer.

Yo, el más pobre de todos los dioses, y mi pobre México".)

Aquí no se debe investigar la cuestión de qué conflictos religiosos impulsaron al mismo Heine a tratar exactamente esta materia poniendo a la Madre de Dios muy venerada entre los cristianos de la confesión católica contra el dios

${ }^{33} \mathrm{Ibid} .$, p. 60. 
llamado pagano. Aquí solamente interesa cómo es que Heine refleja la visión general de la transformación que se operó con este dios mexica en Europa. Heine utiliza la forma del romance para atribuir al dios mismo la idea de transformarse en el diablo:

"Nach der Heimat meiner Feinde, Die Europa ist geheißen, Will ich flüchten, dort beginn' ich Eine neue Karrière.

"Ich verteufle mich, der Gott Wird jetzund ein Gottseibeiuns:

Als der Feinde böser Feind Kann ich dorten wirken, schaffen. "Quälen will ich dort die Feinde, Mit Phantomen sie erschrecken Vorgeschmack der Hölle, Schwefel Sollen sie beständig riechen. "Ihre Weisen, ihre Narren Will ich ködern und verlocken... "Mein geliebtes Mexiko, Nimmermehr kann ich es retten, Aber rächen will ich furchtbar Mein geliebtes Mexiko". ${ }^{34}$

(“A la patria de mis enemigos que se llama Europa quiero huir, alli empezaré una nueva carrera. "Me endiablare, el dios en este instante se convierte en el espíritu maligno.

Como el enemigo de los enemigos puedo allá obrar, luchar.

"Allá quiero maltratar a los enemigos, asustarlos con quimeras presentimientos del infierno, siempre deben oler azufre. "A sus sabios, a sus locos los quiero engatusar y seducir... "Mi muy querido México, nunca más puedo salvarlo, 
pero quiero vengar pavorosamente

a mi muy querido México".)

De esta manera Heine cambia la realidad de la recepción del dios principal mexica como apariencia diabólica "Vitzliputzli" en un acto de autoelaboración espontánea y venganza del ser sobrenatural de procedencia amerindia, en contra de los cristianos que impusieron el catolicismo con una brutalidad inexorable al mundo mexicano y subyugaron todo lo que les repugnaba en nombre de la Virgen María.

El rechazo de la ignorancia e irreverencia hacia los pueblos extranjeros, sus formas de vida y creencias, transfiriéndolo al pensamiento y obras divinas, es para Heine un intento esencial de precisar su propia posición. Sin embargo, refleja, sobre todo, el desarrollo que tal comportamiento tuvo al comienzo de la época cọlonial, generalizándose en la Europa central.

Es interesante cómo se utiliza, en adelante, esta figura del diablo en la literatura, fuera de las piezas de títeres y basándose en parte en las antiguas descripciones de viajes y, asimismo, en el papel que Heine adscribe a Vitzliputzli. Además del intento de Heine para apoderarse así del tema, es importante la manera cómo Richard y Paula Dehmel quisieron introducir al Fitzeputze en la literatura para niños, basándose en una obra de Karl Glocke, publicada en 1839 con el título: Fitzliputzli und sein Freund Kockelmock (Fitzliputzli y su amigo $K$.). ${ }^{35}$

El título de un tomo de poemas para niños que publicaron los autores Dehmel en 1900 es: Fitzeputze. Allerhand Schnickschnack für Kinder (Fitzeputze. Diversas sandeces para niños).$^{36}$

El libro se basa en una pieza teatral escrita para sus propios hijos, que en 1899 ofreciera escenas de transformaciones, danzas, cantos, milagros y aventuras bajo el título Fitzeputze, con base en cuentos populares. En el frontispicio del mencionado libro encontramos al dios principal mexica, también escrito como Vitzliputzli y Witzlilopochtli. Se tiene que considerar que generalmente se caracteriza la lírica de Richard Dehmel como semi-comprensible. ${ }^{37}$ En este contexto describe como sigue al "héroe titular", reduciendo su capacidad de pronunciar al nivel de un párvulo:

${ }^{35}$ Véase Fitzliputzli und sein Freund Kockelmock. Lidia. Der Zigeunerknabe. Drei neue Märchen von Karl Glocke. Berlin, 1839.

${ }^{36}$ Paula y Richard DEHMEL, Fitzeputze. Allerhand Schnickschnack für Kinder. Mit Bildern von Ernst Kreidolf. Historische Kinderbücher 11. Leipzig, 1968.

${ }^{37}$ Eduard ENGEL, Geschichte der deutschen Literatur von den Anfängen bis in die Gegenwart, t. II. Leipzig/Viena, 1907, pp. 1046 y 1048. 
Pst, sagt Hater, Fitzebott war einmal ein lieber Dott, der auf einem Tuhle saB und gebratne Menschen aß; huh!

(iSilencio! dice el padre, Fitzebott

fue una vez un dios amable que estaba sentado en una silla y comía hombres asados; ¡uh!) ${ }^{38}$

La manera en que la antropofagia es articulada como único criterio demuestra claramente hasta qué punto la utilización de la imagen y caracterización del dios principal mexica como espectro de niños es verdaderamente peligrosa y de ningún modo ridícula. Hay riesgo si se quiere llevar esa visión diabólica del dios mexica hacia su degradación total.

Utilizar su nombre y dibujar su apariencia en diferentes contextos demuestra que el Vitzeputze tuvo ulterior importancia dentro del uso del idioma alemán - y no solamente en las piezas de títeres. Como muestra se ha escogido lo que Arno Holz expresa en 1890 acerca de un dibujo infantil, ejemplificando con eso la razón de ser y las leyes del arte:

Dieser "Süldat" ist das, was ich suchte. Nämlich eine jener einfachen künstlerischen Tatsachen, deren Bedingungen ich kontrollieren kann. Mein Wissen sagt mir, zwichen ihm und der "Sixtinischen Madonna" in Dresden besteht kein Art-, sondern nur ein Gradunterschied. ...ist genau dasselbe Gesetz tätig gewesen, nach dem die "Sixtinische Madonna" eben die "Sixtinische Madonna" geworden ist und nicht etwa ein Wesen, das zum Beispiel sieben Nasen und vierzehn Ohren hat. Dinge die ja sicher auch nicht außer aller Welt gelegen hätten! Man braucht nur an die verzwickten mexikanischen Vitzliputzlis und die wunderlichen Ölgötzen Altindiens zu denken. ${ }^{39}$

(Este "soldado" es lo que he buscado. Es decir, uno de esos simples hechos artísticos cuyos alcances puedo controlar. Mis conocimientos me dicen que entre esto y la "madona sixtina" en Dresde no existe ninguna diferencia de carácter sino solamente una de grado...

${ }^{38}$ P. Y R. DeHMEL, op. cit., p. 5.

${ }^{39}$ Arno Holz, "Die Kunst. Ihr Wesen und ihre Gesetze", en Uber die Schönheit häBlicher Bilder. Dichter und Schriftsteller über Maler und Malerei (1880-1933). Berlín, Hrsg. v. W.Tenzler, 1982, pp. 12 y ss. 
Exactamente por la misma norma la "madona sixtina" se ha convertido precisamente en la "madona sixtina", y no en un ser que, por ejemplo, tiene siete narices y catorce orejas. ¡Cosas que seguramente tampoco estarían afuera de todo el mundo! Solamente se necesita pensar en los curiosos Vitzliputzlis mexicanos y los ídolos caprichosos de la antigua India.)

Se demuestra que el nombre del dios mexica en este conjunto se ha convertido en nombre genérico. Se tiene que agregar que la recepción del arte de la América prehispánica, asi como la atención especial de los artistas y los comentaristas de arte europeos, solamente han empezado a formarse en los decenios más recientes.

En la tirantez de las relaciones entre el realismo y la monstruosidad en esas sociedades mexicanas del tiempo de la Conquista, socialmente muy diferenciadas, Huitzilopochtli aparece en una posición, por lo general, poco tomada en cuenta. La mayoría de las culturas centromexicanas prestaron poca atención a ese "colibri del sur" mexica. Por eso es claro que se cambia el resultado si se orienta más y más a una observación científicamente determinada de Huitzilopochtli. Entonces, esa figura simbólica del Vitzeputze se aleja más que nunca y pierde su significado como símbolo diabólico de conceptos de mundos ajenos y de diferentes maneras de representaciones artísticas.

Separada de su sentido original, la denominación puede tener mayor importancia en el uso del idioma alemán. En parte, refleja la historia espiritual de los siglos que siguieron al descubrimiento del continente americano por los europeos y sigue siendo una de las manifestaciones curiosas del ingenio humano al apropiarse de lo extraño, de lo exótico, y al explicarse lo que parece ser inexplicable. 